\title{
An example of national scientific collaboration during the COVID-19 pandemic: Turkish Thoracic Society Early Career Members Taskforce Group's contribution to accessing reliable scientific knowledge
}

\author{
Dilek Karadoğan ${ }^{1}$, Nagehan Emiralioğlu², Fatma T. Akyil ${ }^{3}$, Canan G. Gürkan ${ }^{4}$, Aycan Yüksel ${ }^{5}$, Feride Marim6 ${ }^{6}$, Zehra N. \\ Töreyin ${ }^{7}$, Hüseyin Arikan ${ }^{8}$, Tuğba Ş. Eyüboğlu ${ }^{9}$, İrem Şerifoğlu ${ }^{10}$, Abdulsamet Sandal ${ }^{11}$, Tuğba R. Gürsoy ${ }^{9}$, Metin Akgün ${ }^{12}$
}

\begin{abstract}
AFFILIATION
1 Department of Chest Diseases, Faculty of Medicine, Recep Tayyip Erdogan University, Rize, Turkey

2 Department of Paediatric Pulmonology, Faculty of Medicine, Hacettepe University, Ankara, Turkey

3 Department of Chest Diseases, Yedikule Chest Diseases and Thoracic Surgery Training and Research Hospital, Istanbul, Turkey

4. Department of Chest Diseases, Sureyyapasa Chest Diseases and Thoracic Surgery Training and Research Hospital, Istanbul, Turkey 5 Department of Chest Diseases, Faculty of Medicine, Ufuk University, Ankara, Turkey

6 Department of Chest Diseases, Faculty of Medicine, Kütahya University of Health Sciences, Kutahya, Turkey

7 Department of Occupational Health and Diseases, Adana City Research and Training Hospital, Adana, Turkey

8 Internal Medicine Intensive Care Unit, Dursun Odabas Medical Center, Yüzüncü Yll University, Van, Turkey

9 Department of Paediatric Pulmonology, Faculty of Medicine, Gazi University, Ankara, Turkey
\end{abstract}

Popul. Med. 2020;2(September):27
10 Department of Chest Diseases, Ankara City Hospital, Ankara, Turkey 11 Department of Occupational Health and Diseases, Ankara Occupational and Environmental Diseases Hospital, Ankara, Turkey 12 Department of Chest Diseases, Faculty of Medicine, Ataturk University, Erzurum, Turkey

\section{CORRESPONDENCE TO}

Dilek Karadoğan. Department of Chest Diseases, Faculty of Medicine, Recep Tayyip Erdogan University, Rize, 53020, Turkey.

E-mail: cakmakcidilek@yahoo.com ORCID ID: https://orcid.org/00000001-5321-3964

\section{KEYWORDS}

scientific knowledge, COVID-19, early career members

Received: 18 June 2020, Revised: 30 July 2020 ,

Accepted: 2 August 2020

https://doi.org/10.18332/popmed/125944

\section{Dear Editor,}

The COVID-19 pandemic began in December 2019 in Wuhan, China, and spread over the world, swiftly becoming an alarming international outbreak. Following the first case detected on 11 March 2020 in Turkey, the outbreak caused a national emergency as well. Due to the novelty of this public health issue, the Turkish Thoracic Society Early Career Members Taskforce Group's (TTS ECMTG) contribution was requested throughout the pandemic in order to keep the society updated, based on reliable scientific publications. Also, some databases, including COVID-19 resources, have been universally accessible to all scientists to maximize knowledge sharing. Since there is a need for rapid information to shed light on the unknowns about COVID-19, an enormous amount of publications was produced in such a short time, especially in the first couple of months of the pandemic ${ }^{1}$. Therefore, any new scientific finding was open to modification and falsification. This meant that our knowledge was continuously changing during the pandemic period, and it has been challenging for the physicians to stay updated on a substantial number of new publications. Besides, it brought out a significant concern for clinicians, which was to critically evaluate multiple research results and decide which ones would guide their clinical approach. ECMTG thus decided to share, with members of TTS and other Turkish clinicians, brief summaries of the most reliable recent literature to ensure access to robust scientific knowledge, and to keep all physicians informed and updated regarding the new publications. The TTS ECMTG aimed to evaluate the scientific publications rigorously, avoiding disinformation, and to summarize reliable information for all members of TTS working in the field and fighting against the COVID-19 pandemic.

This letter aims to give a perspective of our group's effort, as an example of dedicated teamwork at the time of a pandemic. The TTS ECMTG was established in September 2019 and aimed for future national and international collaborations. By the time of the pandemic, the group had 75 members under the age of 40 years, mostly consisting of pulmonologists. Although this group was established recently, collaborative teamwork has been demonstrated by its members, even from the beginning of the pandemic. It was expected that ECMTG members would contribute to teamwork actively. In this period, when the pandemic had reached a peak, reliable and easily accessible resources were needed to inform other pulmonologists and clinicians. 
The foremost tasks of the group were a comprehensive literature search, follow up on new data, and share of any concrete findings with a Whatsapp group. In this period, many unaccepted publications were published online in literature databases, and among these, scientific articles had to be carefully selected. So, among group members, a team was developed for checking not only the articles to be summarized but also producing drafts of summaries, as the group had a broad academic spectrum of members, from residents to associate professors aged $<40$ years. The team, comprising 12 dedicated and qualified members, developed a standard template for article summaries; it also aimed to give a style to ECMTG and make that newly developed group different from other assemblies of the society regarding article summarizing style. From the beginning of article selection, the team became responsible for selecting novel and reliable publications and sharing them with all members of the group. The journal quality and novelty of the research were the primary considerations during the selection of articles. Each of these articles was then assigned to a member by following a first come, first served' style for duty sharing. Also, some new guidelines regarding COVID-19 were summarized during this period. All articles that were summarized in Turkish were checked by that team and re-evaluated when necessary after corrections by the summarizing member. It was emphasized that, in the preparation of a summary, the critical points of the article should be stated rather than merely translated. The checking team specifically considered this point, and most team members reviewed and discussed the summaries together via another Whatsapp group. After this process, the articles were shared with the other ECMTG members. Finally, the summaries were shared with TTS members via e-mail groups.

Between 20 March and 20 May 2020, a total of 141 articles on COVID-19 were summarized in the Turkish language by the group. Ninety-eight per cent of the articles were in English. At first, each summary was shared via WhatsApp groups and e-mail groups. Afterwards, three e-books were published on the web page of TTS and shared via e-mails, as well as TTS's official WhatsApp, over all the country. In this regard, more than 4000 members of TTS accessed the summaries and e-books. Besides TTS members, physicians who were not pulmonologists, but working in COVID-19 units, were reached via social-media pages of the TTS. Articles and summaries were re-evaluated at the preparation of the e-books, re-checked from the final situation of the original article that had controversial findings, and updated accordingly, such as articles on efficacy of azithromycin and hydroxychloroquine combination ${ }^{2}$. These finalized e-books have been shared with the whole country by using technology instruments that narrow the gaps during this period; such as social-media channels, e-mail and also the official WhatsApp ${ }^{3-5}$. During the pandemic period, webinars were organized by the American Thoracic
Society (ATS) and European Respiratory Society (ERS). Thus, essential notes obtained from these webinars have been shared with the other members ${ }^{6}$. Additionally, the team members prepared review articles, regarding the most relevant knowledge on COVID-19, which are in the publication process $^{7-9}$. Besides, this crisis has affected face-toface meetings and the communication of members who are living in different parts of the country; an online meeting was organized among the group members after completing the final e-book, the record of the Zoom meeting is available from YouTube and it gives a reflection of the source of the group's motivation - solidarity and collaboration ${ }^{10}$. As knowledge about COVID-19 is still limited and there are many unknown answers to questions, despite ongoing clinical trials about its management and treatment, sharing this information with others has been crucial in managing the crisis. The result has been that we have received positive feedback from the group members and other pulmonologists about the effectiveness of this collaboration. The summaries clarified some issues regarding COVID-19, such as pathogenesis, coagulopathy, transmission, and treatment complications, especially cardiotoxicity. For example, many centers decided to postpone spirometric and bronchoscopic procedures, accordingly. Colleagues from around the country pointed out that the way the virus is transmitted and the use of personal protective equipment have become clearer. In addition, the summaries regarding the management of respiratory failure clarified that non-invasive mechanical ventilation (NIV) could be used in treatment safely, and many intensive care physicians began to apply NIV to COVID-19 patients. Receiving positive feedbacks from the readers and witnessing the great interest of the TTS members was a great honor for the whole group. During this time, we have also projected future studies by considering the findings reached in the summarized literature.

In summary, we would like to present the effectiveness of our collaboration as an example of teamwork in a limited period, also pointing out the usefulness of modern communication tools such as WhatsApp (smartphones) and e-mails. We have demonstrated the importance of scientific collaboration and organization for accessing updated information with this teamwork, a precedent of cooperation during a global health crisis. We believe that human ingenuity works better when team spirit takes the helm. We would like to conclude with the following quotation: 'All a man could win in the conflict between plague and life was knowledge and memories' (Albert Camus, The Plague).

\section{REFERENCES}

1. Rochwerg B, Parke R, Murthy S, et al. Misinformation During the Coronavirus Disease 2019 Outbreak: How Knowledge Emerges From Noise?. Crit Care Expl. 2020;2(4):e0098. doi:10.1097/CCE.0000000000000098

2. International Society of Antimicrobial Chemotherapy. Official Statement from International Society of Antimicrobial 
Chemotherapy (ISAC). https://www.isac.world/news-andpublications/official-isac-statement. Accessed July 30, 3030.

3. Türk Toraks Derneği. COVID-19 Makalelerinin Özetleri. https://www.toraks.org.tr/site/sf/nmf/pre_ migration/ 663c46acc9025e0a1561d1c7241b00b1fd63e8b0d3b6d 32c24af01eb0aa138cc.pdf. Published April 2020. Accessed July 30, 2020.

4. Türk Toraks Derneği. Erken Kariyer Görev Grubu COVID-19 Makale Özetleri- Cilt II. https://www.toraks.org.tr/site/sf/nmf/ a5601e7e07df8f64e6 pre_migration/ba1af1d6fef881a589ded fad1fe03dd34fb0399092de2e.pdf. Published April 2020. Accessed July 30, 2020.

5. Türk Toraks Derneği. Erken Kariyer Görev Grubu COVID-19 Makale Özetleri- Cilt III. https://www.toraks.org.tr/site/sf/ nmf/pre_migration/7d53d37b429db5b0090ec55555c135192 8987c53d84cc8505d22a0ed35036c9.pdf. Published May 2020. Accessed July 30, 2020.

6. Türk Toraks Derneği. ATS-ERS ortak webinarı "COVID-19'a Global Bakış": 13.04.2020. https://www.toraks.org.tr/site/ sf/nmf/pre_migration/c844d13bbfcc0596474255c4fca40fa 1f4b79e9eeff04752d071e4119d29f69d.pdf. Accessed July 30, 2020.

7. Tokgöz Akyll F, Karadoğan D, Gündüz Gürkan C, et al. What We Learned about COVID-19 So Far? Notes from Underground. Turk ThoracJ.2020;21(3):185-192. doi:10.5152/TurkThoracJ.2020.20052

8. Marim F, Karadogan D, Sismanlar Eyuboglu T, et al. Lessons Learned so Far from the Pandemic: A Review on Pregnants and Neonates with COVID-19. Eurasian J Med. 2020;52(2):202-210. doi:10.5152/eurasianjmed.2020.20118

9. Yuksel A, Karadogan D, Gunduz Gurkan C, et al. Unclear Issues Regarding COVID-19. Eurasian J Med. 2020;52(2):191-196. doi:10.5152/eurasianjmed.2020.20092

10. TTD Erken Kariyer Görev Grubumuzu tanıyalım. [Let's get to know our TTD Early Career Members Taskforce Group]. Youtube. https://www.youtube.com/watch?v=a1vlmSnak8g. Published May 14, 2020. Accessed July 30, 2020.

CONFLICTS OF INTEREST

The authors have completed and submitted the ICMJE Form for Disclosure of Potential Conflicts of Interest and none was reported.
PROVENANCE AND PEER REVIEW

Not commissioned; externally peer reviewed.

FUNDING

There was no source of funding for this research. 